\title{
Investigating Nepal's Gross Domestic Product from Tourism: Vector Error Correction Model Approach
}

\author{
Basanta Dhakal, Azay Bikram Sthapit, Shankar Prasad Khanal \\ Central Department of Statistics, Tribhuvan University, Kathmandu, Nepal \\ Email address: \\ basantadh@gmail.com (B. Dhakal) \\ ${ }^{*}$ Corresponding author \\ To cite this article: \\ Basanta Dhakal, Azay Bikram Sthapit, Shankar Prasad Khanal. Investigating Nepal's Gross Domestic Product from Tourism: Vector Error \\ Correction Model Approach. American Journal of Theoretical and Applied Statistics. Vol. 5, No. 5, 2016, pp. 311-316. \\ doi: $10.11648 /$ j.ajtas.20160505.20
}

Received: August 31, 2016; Accepted: September 9, 2016; Published: September 28, 2016

\begin{abstract}
This study tries to examine long run and short run relationship of foreign exchange earnings from tourism and average expenditure of international tourists towards share of gross domestic product (GDP) of Nepalese tourism by using Vector Error Correction Model (VECM). A multivariate time series analysis has been applied from the period of 1991 to 2014 tourism data of Nepal. The results of Johansen test of co-integration indicates there is one co-integrated vector under 4 lags of length among the share of gross domestic product of Nepalese tourism, foreign exchange earnings from tourism and average expenditure of international tourist. The long run relationship based on vector error correction model has indicated that coefficient of GDP elasticity with respect to average expenditure per visitor is more elastic as compare to coefficient of GDP elasticity with respect to foreign exchange earnings from tourism. The results of Granger causality analysis have depicted that there exists bidirectional causal relationship between GDP and expenditure per visitor and unidirectional causal relationship exists between GDP and foreign exchange earnings from tourism.
\end{abstract}

Keywords: Augmented Dickey Fuller Test, Co-integration, Error Correction, Granger Causality

\section{Introduction}

Tourism industry earns the gross revenue and foreign exchange earnings which play an important role in economic development of a nation. "Therefore it is a generator of foreign exchange at the national level and also fasted growing industry in the global economy[1]".Tourism is now rightly added the long list of established industries with tremendous economic and social potentiality. The income generation and employment capability of the industry are quite considerable. "In fact tourism industry especially for developing countries acts as a greatest leveler in time of economic recessions [2]". So, tourism is a vehicle for economic development for the developing countries. It creates a flow of foreign currency into the economy of host country. It directly contributes the current account of the balance of payment.

Tourism is many faceted phenomenons which strengthens the economies of tourism destinations and forges bonds of international-national and inter-regional relationship. "Travel and tourism have taken a place among the world industries and it offers a significant share in Gross Domestic Product (GDP), employment and different opportunities of developing countries for their better growth. Tourism destinations behave as dynamic evolving complex system, encompassing numerous factors and activities which are interdependent and whose relationships might be nonlinear [3]". "The success of tourism in any country depends on the ability of that country to sufficiently develop, manage and market the tourism facilities and activities in that country [4]". The development of tourism, especially developing countries like Nepal, requires the upgrading of infrastructure and other specific facilities related to tourism such as hotel and restaurants, tourist resorts, entertainment centers, transportation services, sales outlet of curios, handicraft, amusement parks, cultural activities etc. In the less developed 
country, tourism is more effective than other industries for generating income and employment because there is a limited alternative opportunities for the development of nation.

There are various empirical studies analyzing the tourism industry's contribution to the economic growth of Nepal. Some of significant works are Berger [5], Khadka [6], and Pradhananga [7] assessed the economic impact of tourism in Nepal using Input-Output Model. Similarly Shrestha [8], Sharma [9], and Upadhyaya [10] analyzed economic impact of tourism using simple regression model in their study. Gautam [11] and Dhungel[12] analyzed the relationship between tourism and economic growth in Nepal using Cointegration analysis and error correction method. Similarly Paudel [13] also examined the impact of tourism and other related macroeconomic variables on the economic growth of Nepal by deriving tourism income multiplier from the Keynesian macroeconomic model.

The several studies mention that tourism provides a significant contribution to national income along with generating employment sectors such as hotel, restaurant, traveling, handicraft etc as indirect contribution. Keeping in view of this reality, the present paper attempts to investigate the long run and short run relationship of foreign exchange earnings from tourism and average expenditure of international tourists towards share of Gross Domestic Product of Nepalese tourism by using Vector Error Correction Model (VECM) and Granger causality.

\section{Methods}

All analysis and discussion are based on published source of secondary data from the period of 1991 to 2014 obtained from Nepal tourism Statistics Published by Ministry of Tourism and Civil Aviation [14].All the statistical analysis has been performed by using STATA 9.0, College Station, Texas, USA.

The vector error correction model has been used to test the causality among the variables: share of gross domestic product of tourism (GDP), foreign exchange earnings from tourism (EARN) and average expenditure per visitor (EXPV).

$$
\mathrm{U}=(\mathrm{GDP}, \mathrm{EARN}, \mathrm{EXPV})
$$

Where GDP is dependent variable and EARN and EXPV are explanatory variables.

Augmented Dickey[15, 16] Fuller test has been used to test the stationary or non-stationary of the data. The Augmented Dickey-Fuller test is referred to the t-statistics of $\delta_{2}$ coefficient on the following regression:

$$
\Delta \mathrm{Yt}=\delta_{0}+\delta_{1 \mathrm{t}}+\delta_{2 \mathrm{t}} \mathrm{Y}_{\mathrm{t}-1}+\sum_{i=1}^{p} \alpha_{\mathrm{i}} \Delta \mathrm{Y}_{\mathrm{t}-1}+\varepsilon_{\mathrm{t}}
$$

The ADF regression tests for the existence of unit root of $Y_{t}$ namely in the logarithm of all model variable at time $t$, variable $\Delta \mathrm{Y}_{\mathrm{t}-1}$ expresses the first difference with $\mathrm{p}$ lags and final $\varepsilon_{\mathrm{t}}$ is the variable that adjust the errors of autocorrelation. The coefficients $\delta_{0}, \delta_{1}, \delta_{2}$ and $\alpha_{i}$ are being estimated. The null hypothesis and alternative hypothesis for the existence of unit root in variable $\mathrm{Y}_{\mathrm{t}}$ are:

Null hypothesis $\left(\mathrm{H}_{0}\right): \delta_{2}=0$ against alternative hypothesis $\left(\mathrm{H}_{1}\right): \delta_{2}<0$

This study has been used Akaike Information Criteria (AIC) or Schwartz Bayesian Information Criteria (SBIC) for selecting lags order to determine the optimal specification of equations [17]. The appropriate order of the model is determined by computing co-integrating equation over a selected grid of values of the number of lags $p$ and finding that value of $\mathrm{p}$ at which the AIC or SBIC attain the minimum. $\mathrm{AIC}$ and SBIC has been computed using equation (3) and (4).

$$
\begin{array}{r}
\mathrm{AIC}=\mathrm{T} \ln (\text { sum of square of residuals })+2 \mathrm{n} \\
\mathrm{SBIC}=\mathrm{T} \ln (\text { sum of square of residuals })+\mathrm{n} \ln \mathrm{T}
\end{array}
$$

Where $n$ is number of parameters estimated and $T$ is number of usable variables

Johansen Co-integration test [18] has been used to determine the number of co-integrating vectors among the variables and then the Johansen VECM framework can be expressed as:

$$
\Delta \mathrm{Yt}=\mathrm{V}+\alpha \beta^{\prime} \mathrm{Y}_{\mathrm{t}-1}+\sum_{i=1}^{p-1} \Phi_{\mathrm{i}} \Delta \mathrm{Y}_{\mathrm{t}-1}+\delta_{\mathrm{i}}+\varepsilon_{\mathrm{t}}
$$

Where $\delta$ is the $\mathrm{kx} 1$ vector of parameter that implies the quadratic time trend. Similarly, $\beta$ is coefficient of cointegrating equation and $\alpha$ is the adjustment coefficient. $\mathrm{V}$ is a $\mathrm{kx} 1$ vector of parameters.

Johansen's approach derives two likelihood estimators for determining the number of co-integration vectors: a trace test and a maximum Eigen value test

The Maximum Eigen value statistic tests the null hypothesis of $\mathrm{r}$ co-integrating relations against the alternative of $\mathrm{r}+1$ co-integrating relations for $\mathrm{r}=0,1,2 \ldots \ldots \ldots \mathrm{n}-1$. It is computed as

$$
R \boldsymbol{m a x}\left(\frac{\mathrm{r}}{\mathrm{n}}+1\right)=-T * \ln (1-\lambda)
$$

Where $\lambda$ is the maximum Eigen value and $\mathrm{T}$ is the sample size.

Trace statistics investigates the null hypothesis of $\mathrm{r}$ cointegrating relations against the alternative of $\mathrm{n}$ cointegrating relations, where $n$ is the number of variables in the system for $r=0,1,2 \ldots \ldots \ldots n-1$. It is computed through the use of the following formula:

$$
\operatorname{Rtrace}\left(\frac{\mathrm{r}}{\mathrm{n}}\right)=-T * \sum_{i=r+1}^{n} \ln (1-\lambda \mathbf{i})
$$

In this test, the null hypothesis of $\mathrm{r}$ co-integrating vectors is tested against the alternative hypothesis of $\mathrm{r}+1$ cointegrating vectors.

Vector Error Correction Model (VECM) has been used to test the long run relationship between target variables and explanatory variables. For this purpose, consider a Vector Autoregressive (VAR) with lag order $\mathrm{p}$ which is expressed as

$$
\mathrm{Yt}=\mathrm{V}+\mathrm{A}_{1} \mathrm{Y}_{\mathrm{t}-1}+\mathrm{A}_{2} \mathrm{Y}_{\mathrm{t}-2}+\mathrm{A}_{3} \mathrm{Y}_{\mathrm{t}-3}+\cdots \ldots \ldots \ldots \ldots+\mathrm{A}_{\mathrm{p}} \mathrm{Y}_{\mathrm{t}-\mathrm{p}}+\varepsilon_{\mathrm{t}}
$$


Where $\mathrm{Yt}$ is a $\mathrm{Kx} 1$ vector of variable, $\mathrm{V}$ is a $\mathrm{kx} 1$ vector of parameters, $A_{I}, A_{2}, A_{3}, \ldots \ldots \ldots \ldots A_{p}$ are $k x k$ matrices of parameters, and $\varepsilon_{\mathrm{t}}$ is a $\mathrm{kx} 1$ vector of disturbances having mean 0 and sum of covariance matrix is identically and independently distributed (i.i.d.) normal over a time. Any Vector Autoregressive Model [19] can be rewritten as Vector Error Correction by using some algebra which can be expressed as

$$
\Delta \mathrm{Yt}=\mathrm{V}+\Pi \mathrm{Y}_{\mathrm{t}-1}+\sum_{i=1}^{P-1} \Phi_{\mathrm{i}} \Delta \mathrm{Y}_{\mathrm{t}-\mathrm{i}}+\varepsilon_{\mathrm{t}}
$$

Where $\Pi=\sum_{j=1}^{P} \mathrm{~A}_{\mathrm{j}}-\mathrm{I}_{\mathrm{k}}$ and $\Phi \mathrm{i}=-\sum_{j=i+1}^{P} \mathrm{~A}_{\mathrm{j}}$

If co-integration has been detected between the series, there exists a long term equilibrium relationship between them, and VECM is applied in order to evaluate the short run properties of the co-integrated series. In case of no cointegration, VECM is no longer required and directly proceeds to Granger causality test to establish causal links between variables [20].

Granger Causality [21] has been used to test the short run causality between bivariate variables. A general specification of the Granger causality test in bivariate $(\mathrm{X}, \mathrm{Y})$ context can be expressed as:

$$
\begin{array}{r}
\mathrm{Xt}=\lambda \mathrm{t}+\sum_{i=1}^{p} \mathrm{a}_{11} \mathrm{x}_{\mathrm{t}-1}+\sum_{i=1}^{p} \mathrm{~b}_{\mathrm{ij}} \mathrm{y}_{\mathrm{t}-1}+\mu_{\mathrm{t}} \\
\mathrm{Yt}=\lambda_{2 \mathrm{t}}+\sum_{i=1}^{P} \mathrm{a}_{21} \mathrm{x}_{\mathrm{t}-1}+\sum_{i=1}^{P} \mathrm{~b}_{2 \mathrm{j}} \mathrm{y}_{\mathrm{t}-1}+\mu_{2 \mathrm{t}}
\end{array}
$$

In this model, $\mathrm{t}$ denotes time periods, $\mu$ is a white noise error and $\boldsymbol{\lambda}$ is constant parameters.

The null hypothesis and alternative hypothesis for the existence of Granger causality in variables $X_{t}$ and $Y_{t}$ expressed as:

$\mathrm{H}_{0}$ : $\mathrm{X}_{\mathrm{t}}$ does not Granger Cause of $\mathrm{Y}_{\mathrm{t}}$ against $\mathrm{H}_{1}: \mathrm{X}_{\mathrm{t}}$ Granger causes of $Y_{t}$.

$\mathrm{H}_{0}: \mathrm{Y}_{\mathrm{t}}$ does not Granger Cause of $\mathrm{X}_{\mathrm{t}}$ against $\mathrm{H}_{1}$ : $\mathrm{Y}_{\mathrm{t}}$ Granger causes of $\mathrm{X}_{\mathrm{t}}$.

In this model, two tests of analysis can be obtained: the first examines the null hypothesis that the $\mathrm{X}$ does not Granger cause $\mathrm{Y}$ and second test examines the null hypothesis that $\mathrm{Y}$ does not Granger cause $\mathrm{X}$.

Lagrange-Multiplier (L-M) test [22] has been used to test for autocorrelation as well as test for stability of the model. L-M test is not only suitable for testing for autocorrelation of any order but also suitable for models with or without lagged dependent variables. The formula for L-M test statistic of lag $\mathrm{p}$ is:

$$
L M=(T-d-0.5) \ln \left[\frac{\left|\sum \mathrm{c}\right|}{\left|\sum s\right|}\right]
$$

Where $\mathrm{T}$ is the number of observations and $\mathrm{d}$ is the number of coefficients estimated in augmented VAR; $\sum_{c}$ is the maximum likelihood estimate of variance-covariance matrix ( $\sum$ )of the disturbances; $\sum_{\mathrm{s}}$ is the maximum likelihood estimate of $\sum$ from augmented vector autoregressive[23].

Jarque-Bera (J-B) test has been applied for normality of disturbances distribution [24]. It is based on the fact that skewness and kurtosis of normal distribution equal to zero. Therefore the absolute value of those parameters could be a measure of deviation of the distribution from normal.

$$
J B=\frac{n-k}{6}\left[(\text { skew })^{2}+\frac{(\text { Kurt }-3)^{2}}{4}\right]
$$

Where $\mathrm{n}$ is number of observations and $\mathrm{k}$ is number of regressors.

\section{Results and Discussions}

\begin{tabular}{|c|c|c|c|c|c|c|}
\hline \multicolumn{4}{|c|}{ Before first differenced(at level) } & \multicolumn{3}{|c|}{ After first differenced } \\
\hline Variable & Test statistics & $5 \%$ critical value & p value & Test statistics & $5 \%$ critical value & p value \\
\hline ln_GDP & -1.997 & -3.00 & 0.288 & -4.444 & -3.000 & 0.000 \\
\hline ln_EARN & -0.985 & -3.00 & 0.758 & -4.912 & -3.000 & 0.000 \\
\hline $\ln \mathrm{EXPV}$ & -1.883 & -3.00 & 0.340 & -4.503 & -3.000 & 0.000 \\
\hline
\end{tabular}

The first step in co-integration analysis is to test the unit roots in each variable. For this purpose, Augmented Dickey Fuller test is applied on GDP, EARN and EXPV.

Table 1. Results of ADF test.

Table 1 reports the results of the ADF test for the level (before first differenced) as well as for the first differenced of the relevant variables. The results show that unit root test applied to the variables at level fail to reject the null hypothesis of non stationary of all the variables used. It implies that all the variables are non-stationary of all at level.
The null hypothesis is accepted when the series are at first differenced i.e. all variables are stationary at first differenced. This implies that all the variables in the series are integrated of order one, i.e. I (1).For getting optimal lag length for cointegrating analysis, two criteria namely AIC and SBIC have been adopted as shown in Table2.

Table 2. Results of lag order selection.

\begin{tabular}{lllll}
\hline Lag & df & p value & AIC & SBIC \\
\hline 0 &. & 0 & 1.738 & 1.887 \\
1 & 9 & 0.000 & -4.453 & $-3.855^{*}$ \\
2 & 9 & 0.029 & -4.481 & -3.436 \\
3 & 9 & 0.078 & -4.357 & -2.863 \\
4 & 9 & 0.000 & $-5.487 *$ & -3.546 \\
\hline
\end{tabular}

*indicates lag order selected by the criteria 
Table 2 shows that AIC suggested a lag length of 4 as optimal, while SBIC indicated 1 as optimal lag length. But in this series of GDP, EARN and EXPV for co-integration analysis 4 lag length has been adopted because 4 lag of length could be found one co-integrating vector under both trace and maximum Eigen value statistics while one lag length could not be found the co-integrating vector. Co-integration relationship among GDP, EARN and EXPV has been investigated using the Johansen technique which is shown in Table 3 .

Table 3. Results of Johansen test of co-integration.

\begin{tabular}{|c|c|c|c|c|c|}
\hline \multirow{2}{*}{ Null Hypothesis } & \multirow{2}{*}{ Eigen value } & \multicolumn{2}{|c|}{ Trace statistic } & \multicolumn{2}{|c|}{ Max Eigen value statistic } \\
\hline & & $\lambda$ trace & $1 \%$ critical value & $\lambda \max$. & $1 \%$ critical value \\
\hline $\mathrm{H} 0: \mathrm{r}=0$ & . & 61.602 & 35.65 & 41.674 & 25.52 \\
\hline $\mathrm{H} 0: \mathrm{r} \leq 1$ & 0.875 & $19.929 *$ & 20.04 & $18.129 *$ & 18.63 \\
\hline $\mathrm{H} 0: \mathrm{r} \leq 2$ & 0.596 & 1.800 & 6.65 & 1.800 & 6.65 \\
\hline
\end{tabular}

*indicates co-integration vector.

Table 3 reports the results of co-integration test based on Johansen's Maximum likelihood method. Both trace statistic ( $\lambda$ trace) and maximum Eigen value statistics $(\lambda \max )$ indicate that there is at least one co-integrating vector among GDP, EARN and EXPV. It can reject the null hypothesis of no cointegrating vector against under both test statistics at $1 \%$ level of significant. It also can not reject the null hypothesis of at most one co-integration vector against the alternative hypothesis of two co-integrating vectors for both trace and max Eigen value test statistics. Consequently, it can conclude that there is only one co-integrating relationship among GDP, EARN and EXPV. This implies the GDP, EARN and EXPV establish a long run relationship. It clearly opens the way for applying VEC model and the summary of long run relationship between GDP, EARN and EXPV under the Vector Error Correction Model (VECM) can be displayed in Table 4.

Table 4. Results of Long Run Relationship between GDP, EARN and EXPV.

\begin{tabular}{llllll}
\hline Variable & $\begin{array}{l}\text { Coeff. of } \\
\text { Beta }\end{array}$ & S.E. & $\mathbf{z}$ & p value & $\mathbf{9 5 \% C . I . ~}$ \\
\hline $\ln$ _GDP & 1.0000 & & & & \\
$\ln$ _EARN & -0.0064 & 0.107 & -0.06 & 0.952 & $\begin{array}{l}(- \\
0.216,0.203)\end{array}$ \\
$l n \_$EXPV & 1.4278 & 0.181 & 7.90 & 0.000 & $(1.073,1.782)$ \\
CONS. & -9.982 & & & & \\
\hline
\end{tabular}

The long run relationship between number of international tourist and their average length of stay explaining share of GDP for one co-integrating vector for Nepal in the period of 1991-2014 is modeled below (Standard errors are displayed in parenthesis).

$l n \_\mathrm{GDP}=-0.0064\left(\ln \_\mathrm{EARN}\right)+1.4278\left(\ln \_\mathrm{EXPV}\right)-9.983$

If all variables are logarithmic, it may interpret the coefficients in terms of elasticity. So it may say increasing EARN by $100 \%$ produces an impact of almost $0.64 \%$ of GDP. Similarly increasing EXPV by $100 \%$ produces an increment of almost $142.7 \%$ of GDP. Thus coefficient of GDP elasticity with respect to EXPV is more elastic as compare to coefficient of GDP elasticity with respect to EARN. All the variables have established in the model with I(1)and cointegrated, the VECM with one co-integrating relation and 4 lags in each equation has been estimated.

The VECM allows the long run behavior of the variables to converge to their long run equilibrium relationship as well as a wide range of short run dynamics which can be shown in Table 5.

Table 5. Results of Coefficient of error correction terms (ECT).

\begin{tabular}{|c|c|c|c|c|c|}
\hline Variable & $\begin{array}{l}\text { Coeff. } \\
\text { OfECT_1 }\end{array}$ & S.E. & $\mathbf{Z}$ & $\begin{array}{l}\mathbf{p} \\
\text { value } \\
\end{array}$ & 95\% C.I. \\
\hline$\Delta \_l n \_$GDP & -0.566 & 0.382 & $\begin{array}{l}- \\
1.48\end{array}$ & 0.139 & $(-1.315,0.183)$ \\
\hline$\Delta \_$ln_EARN & -0.519 & 0.406 & $\begin{array}{l}- \\
1.28\end{array}$ & 0.201 & $(-1.316,0.276)$ \\
\hline$\Delta \_l n \_$EXPV & -1.036 & 0.156 & $\begin{array}{l}- \\
6.66\end{array}$ & 0.000 & $(-1.341,0.731)$ \\
\hline
\end{tabular}

Table 5 shows the coefficient of error correction term of GDP has the speed of convergence towards equilibrium of 56.6 percent (where $\Delta$ symbolize the difference operator). In the short run GDP are adjusted by 56.6 percent of past years deviation from equilibrium. The large absolute value of the coefficient of ECT shows the speed of adjustment is very rapid towards equilibrium and low absolute values are indicating of slow speed of adjustment. It means that speed of adjustment of EARN towards equilibrium is slow. The coefficient of error correction term of GDP has negative sign and it is statistically insignificant at 5\% level. It implies that the system convergence towards equilibrium but unstable due to the any disturbance in the system. The coefficient of error correction term of EXPV carries negative sign and it is significant at $5 \%$ level. It depicts stability of the system and convergence towards equilibrium path in case of any disturbance in the system. The coefficient of error correction term of EARN is negative but statistically insignificant at 5\% level. It implies that the system convergence towards the equilibrium path and the system will be unstable due to any disturbances.

Finally, in order to analyze short run causal relationship among GDP, EARN and EXPV for the equation in the 
VECM, Granger Casualty Wald test is used for the significance of the lagged variables in that equation.

Table 6. Results of Ganger Wald Causality test.

\begin{tabular}{llll}
\hline Null Hypothesis $\left(\mathbf{H}_{\mathbf{0}}\right)$ & Chi square & df & p value \\
\hline GDP does not Granger cause EARN & 2.321 & 4 & 0.677 \\
GDP does not Granger cause EXPV & 13.744 & 4 & 0.008 \\
EARN does not Granger cause GDP & 13.597 & 4 & 0.009 \\
EARN does not Granger cause EXPV & 9.409 & 4 & 0.052 \\
EXPV does not Granger cause GDP & 76.144 & 4 & 0.000 \\
EXPV does not Granger cause EARN & 34.967 & 4 & 0.000 \\
\hline
\end{tabular}

Table 6 reports the results short run causality among the variable GDP, EARN and EXPV. GDP Granger causes EXPV and EXPV also Granger causes GDP. So bidirectional Granger causality exists between GDP and EXPV. Similarly, EARN Granger causes GDP but GDP does not Granger cause EARN. So, unidirectional Granger causality exists between EARN and GDP. Similarly, EXPV Granger causes EARN but EARN does not Granger cause EXPV i.e. there is unidirectional Granger causality between them

Lagrange-Multiplier test has been used to test for autocorrelation as well as stability of the model under $\mathrm{H}_{\mathrm{o}}$ : There is no autocorrelation at lag order against $\mathrm{H}_{1}$ : There is autocorrelation at lag order.

Table 7. Results of L-M Test of Autocorrelation.

\begin{tabular}{lllll}
\hline Lag & Chi square & df & p value & Decision \\
\hline 1 & 14.163 & 9 & 0.117 & Not significant \\
2 & 8.296 & 9 & 0.505 & Not significant \\
3 & 8.683 & 9 & 0.467 & Not significant \\
4 & 13.120 & 9 & 0.157 & Not significant \\
\hline
\end{tabular}

Table 7 shows that $\mathrm{L}-\mathrm{M}$ test concludes it cannot reject the null hypothesis of no residual autocorrelation at lag order 1 through 4 , so there is no evidence to contradict the validity of the model

Jarque -Bera Test has been applied to test the normality of disturbances distribution under Ho: The disturbances distribute normally against $\mathrm{H}_{1}$ : The disturbances do not distribute normally.

Table 8. Results ofJ -B Test for Normality Distributed Disturbances.

\begin{tabular}{lllll}
\hline Variable & Chi square & df & p value & Decision \\
\hline ln_EARN & 0.459 & 2 & 0.79703 & Not significant \\
ln_GDP & 0.289 & 2 & 0.86559 & Not significant \\
ln_EXPV & 0.574 & 2 & 0.75048 & Not significant \\
ALEL & 0.316 & 6 & 0.97074 & Not significant \\
\hline
\end{tabular}

The J-B test clearly indicates that the disturbances are distributed normally.

\section{Conclusion}

The results of Johansen test of co-integration indicates there is one co-integrated vector that implies there exists long run relationship among the variables GDP, EARN and EXPV under 4 lag of length. The long run relationship based on vector error correction model has indicated that coefficient of GDP elasticity with respect to average expenditure per visitor is more elastic as compare to coefficient of GDP elasticity with respect to foreign exchange earnings from tourism. The results of Granger causality analysis have depicted that there exists bidirectional causal relationship between GDP and expenditure per visitor and unidirectional causal relationship exists between GDP and foreign exchange earnings from tourism. It clears that expenditure per visitor increases GDP and foreign exchange earnings also facilitates the expansion of GDP. The effort should be made to take into account the significant role of foreign exchange earnings in Gross Domestic Product of the country, not only focus on the total number of tourist arrival in the country. But, it is necessary to upgrade the infrastructure and other specific facilities related to tourism such as hotel and restaurants, tourist resorts, entertainment centers, transportation services, sales outlet of curios, handicraft, amusement parks, cultural activities etc. for increasing the expenditure per international visitor.

\section{References}

[1] Gill, N.and, Singh, R.P. (2013). Socio-economic impact assessment of tourism in Pithoragarh district,Uttarakhand. International journal of advancement in remote sensing, GIS and geography.1:1-7.

[2] Ganesh, A. and Madhavi,C.(2007).Impact of tourism on Indian economy-A snapshot.Journal of contemporary research in management $1: 235-240$.

[3] Baggio, R. (2008). Symptoms of complexity in a tourism system. Tourism analysis 13:1-20.

[4] Briassoulis,H. and Straaten, J.V.D.(1999).Tourism and environment-regional, economic, cultural and policy issues (environment and assessment).Springer, USA, vol.6.

[5] Berger,V.(1978).The Economic Impact of Tourism in Nepal: An Input Output Analysis. Phd, Faculty of the Graduate School, Cornell University, Austria.

[6] Khadka,K.R. (1993). Tourism and Economic Development in Nepal. Phd, University of Bradford, UK.

[7] Pradhananga, S.B. (2000).Tourists' Consumption Pattern and Its Economic Impact in Nepal. Phd, Central Department of Economics, Tribhuvan University, Nepal.

[8] Shrestha,H.P. (1998). Tourism Marketing in Nepal. Phd, Faculty of Management, Tribhuvan University, Nepal.

[9] Sharma,O.P.(2001).Tourism Development and Planning in Nepal. Phd, Faculty of Social Sciences, Banaras Hindu University, India.

[10] Upadhyaya, R.P. (2004).A Study of Tourism as leading Sector in Economic Development of Nepal. Phd, Department of Economics,University of Lucknow,India.

[11] Gautam, B.P. (2011). Tourism and economic growth in Nepal.NRB Economic Review 23:18-30.

[12] Dhungel,K.R. (2015).An economic analysis on the relationship between tourism and economic growth: Empirical evidence from Nepal.International Journal of economics and financial management3(2):84-90. 
[13] Paudyal, S.R. (2012). Does tourism really matter for economic growth? Evidence from Nepal.NRB Economic Review 24:5889.

[14] MOTCA (2009-2014).Ministry of Tourism and Civil Aviation. Nepal Tourism Statistics. Government of Nepal.

[15] Dickey, D. and Fuller W. (1979).Distribution of the Estimators for Autoregressive Time Series with a Unit Root. Journal of the American Statistical Association 74: 427-431.

[16] Dickey, D. and Fuller W. (1981). Likelihood Ratio Statistics for Autoregressive Time Series with a Unit Root. Econometrica49: 1057-1072.

[17] Mukhtar,T. and Rasheed, S.(2010). Testing long run relationship between exports and imports: Evidence from Pakistan. Journal of Economic Cooperation and Development, 31:41-58

[18] Johansen, S. (1988).Statistical analysis of co-integration vectors.Journal of Economic Dynamics and Control 12:231254 .
[19] Johansen, S. (1995).Likelihood- based inference in cointegrated vector autoregressive model. Oxford: Oxford University Press.

[20] Becketti, S. (2013).Introduction to time series using stata.College Station's: Stata Press.

[21] Granger, C.W.C. (1981).Some properties of time series data their use in econometric model specification.Journal of Econometrics 16:121-130.

[22] Breusch,T.S. and Pagan,A.R.(1980). The Lagrange multiplier test and its applications to model specification in econometrics. Review of Economic Studies 47:239-253.

[23] Davidson, R. and Mackinnon, G. (1993).Estimation and Inference in Econometrics. New York: Oxford University Press.

[24] Jarque, C.M. and Bera, A. K.(1987). A test for normality of observations and regression residuals. International Statistical Review 55:163-172. 